\title{
Attentional networks efficiency in preterm children
}

\author{
R. PIZZO,${ }^{1}$ S. URBEN,${ }^{1}$ M. VAN DER LINDEN,${ }^{2}$ C. BORRADORI-TOLSA,${ }^{3}$ M. FRESCHI, ${ }^{3}$ \\ M. FORCADA-GUEX, ${ }^{4}$ P. HÜPPI, ${ }^{3}$ AND K. BARISNIKOV ${ }^{1}$ \\ ${ }^{1}$ Child Clinical Neuropsychology Unit, University of Geneva, Geneva, Switzerland \\ ${ }^{2}$ Cognitive Psychopathology and Neuropsychology Unit, University of Geneva, Geneva, Switzerland \\ ${ }^{3}$ Division of Child Development and Growth, Department of Pediatrics, University of Geneva Medical School, Geneva, Switzerland \\ ${ }^{4}$ Division of Neonatology, Department of Pediatrics, University Hospital, Lausanne, Switzerland
}

(Received October 27, 2008; Final Revision August 19, 2009; Accepted August 19, 2009)

\begin{abstract}
Recent studies have reported specific executive and attentional deficits in preterm children. However, the majority of this research has used multidetermined tasks to assess these abilities, and the interpretation of the results lacks an explicit theoretical backdrop to better understand the origin of the difficulties observed. In the present study, we used the Child Attention Network Task (Child ANT; Rueda et al. 2004) to assess the efficiency of the alerting, orienting and executive control networks. We compared the performance of 25 preterm children (gestational age $\leq 32$ weeks) to 25 full-term children, all between $5 \frac{1}{2}$ and $6 \frac{1}{2}$ years of age. Results showed that, as compared to full-term children, preterm children were slower on all conditions of the Child ANT and had a specific deficit in executive control abilities. We also observed a significantly higher correlation between the orienting and executive control networks in the preterm group, suggesting less differentiation of these two networks in this population. (JINS, 2010, 16, 130-137.)
\end{abstract}

Keywords: Attention networks, Inhibition, Orienting, Alerting, Prematurity, ANT

\section{INTRODUCTION}

\section{Attentional and Executive Abilities in Preterm Children}

Recent studies have shown that preterm children have attentional and executive difficulties (Elgen, Lundervild, \& Sommerfeld, 2004), which have anegative impact on school-related performance (Anderson, Doyle, \& Victorian Infant Collaborative Study Group, 2003; Bhutta, Cleves, Cradock, \& Anand, 2002). With respect to attention problems, Breslau, Chilcoat, DelDotto, Andreski, and Brown (1996) studied selective and sustained attention in 6-year-old preterm children with low birth weight (LBW; birth weight between 1500 and $2500 \mathrm{~g}$ ). Results showed that LBW children performed more poorly on selective attention tasks than did normal birth-weight (NBW, birth weight $>2500$ g) children. Taylor, Hack, and Klein (1998) compared the attentional performance of extremely low birth-weight (ELBW, birth weight $<750 \mathrm{~g}$ ) and very low birth-weight (VLBW, birth weight between 1000 and $1499 \mathrm{~g}$ ) children at 5 to 9 years of age with NBW

Correspondence and reprint requests to: Roxane Pizzo, Child Clinical Neuropsychology Unit, FPSE, University of Geneva, 40 bd Pont-d'Arve, 1211 Geneva, Switzerland. E-mail: roxane.pizzo@unige.ch children using similar tasks, as well as on one test of mental set shifting. The ELBW children performed worse than the NBW controls on the sustained attention and set shifting tasks, but not on the measure of selective attention. However, when Taylor, Minich, Klein, and Hack (2004) assessed this same sample longitudinally (from mean ages 7 to 14 years), results showed that ELBW children had greater difficulties even in selective attention. In another study using tests of attention, Shum, Neulinger, O'Callaghan, and Mohay (2008) assessed 45 extremely preterm children $(\leq 27$ weeks of gestation) aged 7 to 9 years. They reported that preterm children had difficulties with working memory, selective attention, and attention shifting abilities. Finally, Elgen et al. (2004) failed to find differences between LBW and NBW groups in selective and sustained attention or in shifting abilities, despite reports from parents suggesting more attention problems in the preterm group. Taken together, findings with respect to attention deficits in preterm children have been inconsistent, especially for selective and sustained attention. These studies have also failed to adequately differentiate among distinct attention skills.

Studies of executive functions in preterm children have demonstrated more consistent deficits on tasks assessing inhibition and attention shifting. Espy, Stalets, McDiarmid, Senn, Cwik, and Hamby (2002) assessed working memory, 
inhibition, and shifting abilities in 29 preterm children with a gestational age (GA) between 28 and 36 weeks and a chronological age (CA) of 2 to 3 years. Results showed that preterm children had inhibition deficits, as measured by responses to a Delayed Alternation Task. Edgin, Inder, Anderson, Hood, Clark, and Woodward (2008) examined inhibition and shifting abilities of 88 preterm children (GA of $<33$ weeks), using scores on a Multi-Search Multi-Location task for 2-year-old children, and Detour Reaching Box scores for 4-year-old children. They concluded that preterm children present inhibition and shifting deficits as early as preschool age, and that these deficits are linked with white matter abnormalities. Harvey, O'Callaghan, and Mohay (1999) examined the executive abilities of 48 ELBW children between the ages of $4 \frac{1}{2}$ and $5 \frac{1}{2}$ years. They observed greater difficulties in planning, sequencing, and inhibition in these children compared with NBW children. Böhm, Katz-Salamon, Lagercrantz, and Forssberg (2002) used the NEPSY battery (Korkman, Kirk, \& Kemp, 2003) to compare a large sample $(n=182)$ of $5 \frac{1}{2} 2$-year-old VLBW children with NBW controls on tests of executive function. These authors observed deficits in initiation, inhibition, and selective attention abilities in the VLBW group. More recently, Deforge, André, Mascoët, Toniolo, Demange, and Fresson (2006) found deficits in attention efficiency in a sample of 71 preterm children (GA between 28 and 36 weeks) at 8 to 10 years. Finally, Bayless and Stevenson (2007) used the Test of Everyday Attention in Children (Manly, Anderson, Nimmo-Smith, Turner, Watson, \& Robertson, 2001) to compare the attention and executive functions in a group of forty 6- to 12-yearold preterm children (GA between 28 and 32 weeks) to full-term children. Results showed that preterm children had difficulties in attention shifting and inhibition.

However, it is unclear from these studies if preterm children have greater weaknesses in some executive skills than in others, or if they have a more general executive deficit. The fact that past studies have sampled heterogeneous groups of preterm children with respect to CA (Bayless \& Stevenson, 2007; Taylor et al., 2004), GA (Espy et al., 2002; Deforge et al., 2006), and birth weight (Breslau et al., 1996) also makes it difficult to draw any firm conclusions. Furthermore, the results of some studies have been based on nonspecific and complex cognitive tasks that do not allow identification of specific deficits in attention or executive functions (Deforge et al., 2006; Edgin et al., 2008). It is also noteworthy that previous research in this area has not been guided by an explicit theory for conceptualizing the links among the different aspects of attention.

Attentional abilities are complex and are composed of different processes that develop throughout childhood and adolescence. They play an important role in school achievement and social adjustment (Eisenberg et al., 2000). Because deficits in these abilities are multidimensional in the preterm population and persist to adulthood (Nosarti, Giouroukou, Micali, Rifkin, Morris, \& Murray, 2007), a theoretical framework is needed to guide research, such as that proposed by Posner and Peterson (1990). According to this model, attention is composed of the three systems: alerting (maintaining vigilance abilities), orienting (ability to shift the attention), and executive control (inhibition abilities).

\section{The Attentional Networks Task}

Fan, McCandliss, Sommer, Raz, and Posner (2002) proposed that these three systems could be assessed with a single behavioral task: the Attention Network Task (ANT). Many studies using the ANT have confirmed the independence of the three systems in terms of cognitive processes and neuronal networks in adults (Fan et al., 2002; Fan, Fossella, Sommer, Yanghong, \& Posner, 2003; Fan McCandliss, Fossella, Flombaum, \& Posner, 2005; Fernandez-Duque \& Posner, 2001). Rueda et al. (2004) adapted a version of the ANT for children and used it with children between the ages of 4 and 10 years. They observed that the three attentional networks were independent even in childhood. Alerting and orienting skills improved until 6 years of age and then stabilized. Indeed, no change in orienting and alerting abilities was found between 6-year-old children and adults in this task. Executive control ability improved up to the age of 7 years, but remained stable after this age, a finding that is consistent with the literature on conflict resolution tasks (Ridderinkhof, van der Molen, \& Band, 1997). More recently, Hrabok, Kerns, and Müller (2006) examined changes in vigilance (i.e., synonymous with alerting), orienting, and executive control abilities in children ages 4 to 5 years. They found age-related improvement on executive control and orienting tasks but not on a vigilance task.

\section{The Attentional Networks in Preterm Children}

Little research on preterm children has assessed the three attentional networks included in Posner and Peterson's model (1990). Snyder, Davis, Burns, and Robinson (2007) observed that a sample of 4- and 5-year-old VLBW children had significantly slower reaction times on orienting, vigilance, and spatial conflict tasks compared with full-term children. The orienting task consisted of a Posner's cuing paradigm. Vigilance was measured with a task using an auditory warning signal (present or not) and the spatial conflict task presented a cognitive conflict between the location of a target and the location of the response (Berger et al., 2000). These three tasks were similar to those included in the Child ANT. Thus, this study was among the first to use attention tasks based on the theoretical model proposed by Posner and Peterson (1990) in a preterm sample. However, the general pattern of performance on the three tasks showed a high rate of accuracy (i.e., ceiling effects), precluding detection of specific deficits in preterm children.

Leclercq, Jambaqué, Picard, Bricout, and Siéroff (2006) assessed the efficiency of the three attentional networks with an adaptation of the Child ANT in seven preterm children (mean GA = 30.2 weeks; range, 28-34 weeks) between 7 and 11 years of age. Results showed that preterm children had a deficit in executive control. Other findings from this study suggested that the effect of distractors was dependent 
on children's ability to orient to the stimuli (Fan et al., 2002). Leclercq et al. (2006) interpreted this finding as an indication that executive control and alerting networks were poorly differentiated in preterm children. Despite the small sample size and limitations related to manner in which the ANT task was modified for this study, the demonstration by Leclercq et al. (2006) of a specific attentional deficit in preterm children provides impetus for further studies of attentional networks in preterm children.

The present study used the version of the original Child ANT by Rueda et al. (2004) to assess the efficiency of the three attentional networks in preterm children. A further aim was to investigate relations between the three attentional networks. Based on findings from the studies of Snyder et al. (2007) and Leclercq et al. (2006), we hypothesized that preterm children would have slower overall reaction times on all task conditions than fullterm children. We also hypothesized that the preterm children would have a less efficient executive control network, even when controlling for their slower response times, and that the three attentional networks would be less well differentiated in preterm children than in full-term controls.

\section{METHODS}

\section{Participants}

The group of prematurely born children was recruited by the Developmental Units of the Children's Hospital of Geneva and the University Hospital of Lausanne. These centers track all preterm children $(<32$ weeks GA) from birth to 8 years of age. From March through July 2006, all preterm children with a GA $<32$ and a CA between $51 / 2$ and $61 / 2$ years who came to the hospital for their annual developmental follow-up were asked to participate in the study. Children with severe disabilities (blindness, hearing loss, cerebral palsy) were excluded, and 2 of 27 families refused to participate. Fourteen girls and 11 boys formed the preterm group in this study with mean CA was 5.83 years $(S D=.27)$. The $\mathrm{GA}$ of this group ranged from 25 to 32 weeks $(M=28.56 ; S D=2.80)$ and birth weight ranged from $600 \mathrm{~g}$ and $1980 \mathrm{~g}(M=1125.6 ; S D=347.2)$. Nine of the children were diagnosed with intra-uterine growth retardation and one child had a Grade 1 intraventricular hemorrhage. None of the children had bronchopulmonary dysplasia. All children were educated in mainstream schools and were not enrolled in special educational learning support services. Using the index of Largo et al. (1989), the mean socioeconomic status (SES) of the preterm children was $4.83(S D=2.43)$. The index is computed on a six-point scale, taking into account the mother's and the father's educational/professional status [ $1=$ high education and/or liberal (i.e., independent) activity and level $6=$ no training and/or a position of employee]. Education and professional status are coded separately, and the scores are then averaged to obtain a family's SES.

The general cognitive abilities of the preterm group were assessed with the Kaufman Assessment Battery for Children (K-ABC; Kaufman \& Kaufman, 1993). Preterm children had a mean Mental Processing Composite score of 100.45
( $S D=18.46)$, with means of $99.96(S D=15.69)$ and 101.17 $(S D=17.82)$, respectively, on the Sequential and Simultaneous Processing scales. As a measure of general cognitive ability was not administered to the control group, we cannot be sure that the control children had similar global cognitive abilities. However, the procedure of controlling for composite ability measures such as IQ in group comparisons has been criticized in a recent review (Dennis, Francis, Cirino, Schachar, Barnes, \& Fletcher, 2009) and is unwarranted given the lack of correspondence between executive skills and general intelligence (Friedman et al., 2006).

The control group consisted of 25 children born at term who had never been diagnosed with learning difficulties or required special educational learning support. Children in the control group were recruited through local schools and matched to the preterm group on CA $(M=5.10$ years; $S D=$ $0.3)$, gender, and SES $(M=4.5 ; S D=2.67)$. Informational letters were sent to parents of children between $5 \frac{1}{2}$ and $6 \frac{1}{2}$ years of age, inviting them to return consent forms.

\section{Materials and Procedure}

The Child ANT was created with the E-prime program (Psychological Software Tools) and was downloaded on a laptop computer from the Internet site of the Sackler Institute for Developmental Psychobiology. The target, a yellow fish, was presented alone or in the center of a horizontal row of five yellow fish. The target was presented either above or below the fixation cross. Children were instructed to keep their eyes on a fixation cross during the task and to respond whether the center fish was facing left or right by pressing the right or the left mouse button. On congruent trials, the flanking fish were pointing in the same direction as the central fish and on incongruent trials the flanking fish were pointing in the opposite direction. On neutral trials the central fish appeared alone (Fan et al., 2002). Each target was preceded by one of the following four cue (asterisk) conditions: a center cue, presented at the location of the fixation cross; a double cue, appearing approximately $1^{\circ}$ above and below the fixation cross at one of which locations the target is presented; a spatial cue, appearing at approximately $1^{\circ}$ above or below the fixation cross at the location of the target; or no cue (see Figure 1).

The task was composed of 24 practice trials and three experimental blocks of 48 trials each. Each block had 12 conditions in equal proportions: three target types (congruent, incongruent, and neutral) and four cues (no cue, central cue, double cue, spatial cue). The task took approximately $20 \mathrm{~min}$ to complete and was administered individually in a quiet room by a qualified clinical psychologist. Informed consent was obtained from parents of children, and the research was approved by the Ethics Committees of both the University of Geneva and the Cantonal Hospital of Geneva.

\section{Analysis}

We compared the efficiency of the alerting, orienting, and executive networks between the two groups based on two 


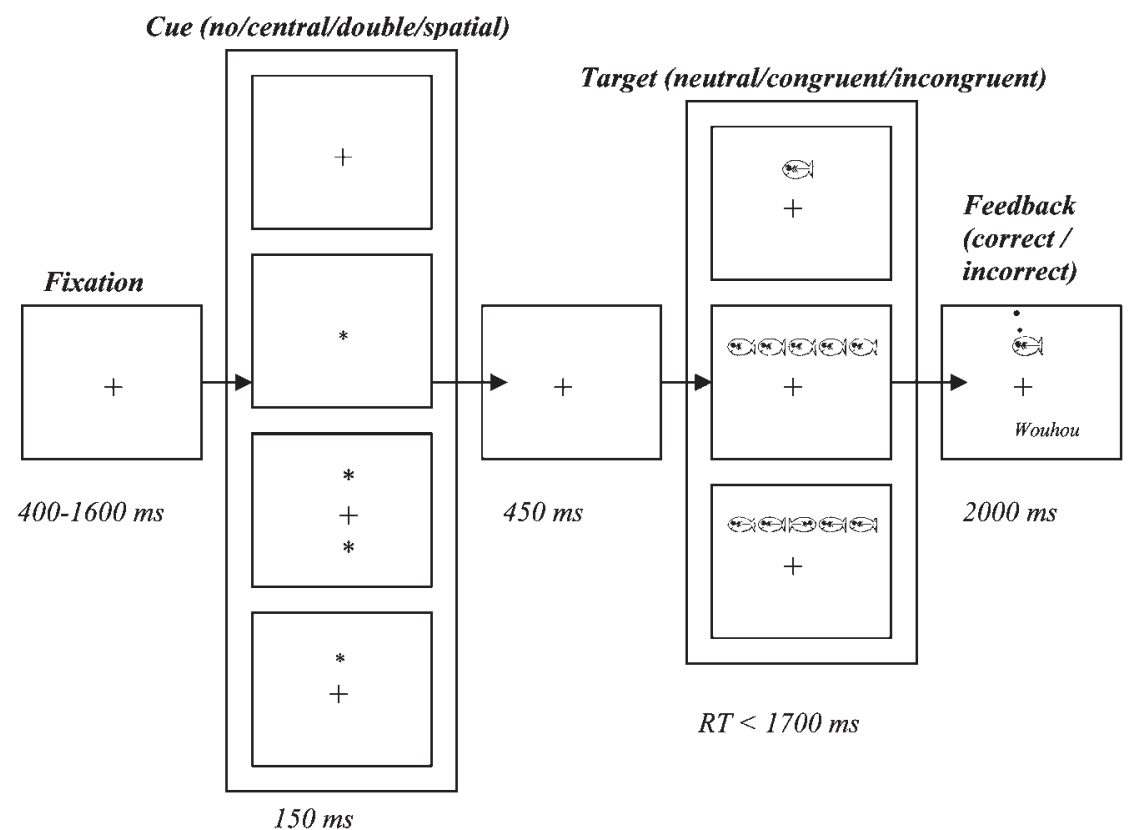

Fig. 1. Schematic of the Child Attention Network Test (Child ANT). The background color is magenta, and the fish are yellow.

scoring methods with one-way analysis of variance (ANOVA). The first method was the subtraction method used by Fan et al. (2002) and adapted by Rueda et al. (2004) for the Child ANT. To calculate the alerting network score using the subtraction method, the median reaction time (MRT) was collapsed across the three flanker types (congruent, incongruent, and neutral) in the no cue condition and in the double cue condition. This collapsed no cue MRT was then subtracted from the collapsed double cue MRT to obtain the alerting network score. To calculate the orienting network score using subtraction method, MRT was collapsed across the three flanker types in the center cue condition and in the spatial cue condition. This collapsed center cue MRT was then subtracted from the collapsed spatial cue MRT to obtain the orienting network score. Finally, to calculate the executive control network score, the MRT was collapsed across the four cue conditions (no cue, center cue, double cue, and spatial cue) in the incongruent condition and in the congruent condition. This collapsed incongruent condition MRT was then subtracted from the collapsed congruent condition MRT to obtain the executive control network score. The measures were calculated using an Excel macro downloaded from Fan's (2001) Web page. Data on error rates were also collected.

In the second, or Relative Interference Ratio method (de Frias, Dixon, \& Strauss, 2006; Spieler, Balota, \& Faust, 1996), we used a relative ratio of MRT to control for possible overall differences in speed among participants. The interference ratio was calculated by first subtracting MRT in the control condition (e.g., no cue condition for the alerting network) from MRT in the experimental condition (e.g., double cue condition for the alerting network), and subsequently dividing this difference by his or her MRT in the control condition (e.g., no cue condition for the alerting network): interference $=($ experimental MRT - control MRT) / control MRT. Only correct responses were considered in computing these values. The interference scores for the different networks were calculated as follows: alerting = (no-cue MRT - double-cue MRT) / double-cue MRT; orienting = $($ center-cue MRT - spatial-cue MRT $) /$ spatial-cue MRT; executive control = (incongruent flanker MRT - congruent flanker MRT) / congruent flanker MRT. Interference scores were expressed as percentages, with higher scores representing greater difficulties in responding to experimental relative to control trials.

Before undertaking these analyses, we verified that the GA and the BW had no impact on the performance of the preterm children $(p>.05)$. Thus, GA and BW were not used as covariates in our analyses. The lack of association between the degree of prematurity (defined in terms of GA and $\mathrm{BW}$ ) and the performance of the preterm children on the Child ANT contrasts with previous findings (Aylward, 2002) but is consistent with observations that neonatal risks account for only limited variability in outcomes within preterm samples (van de Weijer-Bergsma et al., 2008). The data were analyzed using SPSS Version 15, with analyses of network efficiency scores adjusted with Bonferroni alpha correction.

\section{RESULTS}

\section{Performance Across Task Conditions of the ANT for the Preterm and Full-Term Groups}

Table 1 summarizes MRT and error data for the two groups on all 12 task conditions ( 3 flanker types $\times 4$ cue types). Results of ANOVAs comparing the two groups revealed significantly slower MRT and higher error rates for the preterm 
Table 1. Mean performances and (standard deviation) of preterm group and control group

\begin{tabular}{|c|c|c|c|c|c|c|}
\hline \multirow[b]{2}{*}{ Variables } & \multirow[b]{2}{*}{ Group } & \multirow[b]{2}{*}{ Flanker type } & \multicolumn{4}{|c|}{ Warning type } \\
\hline & & & No cue & Central cue & Double cue & Spatial cue \\
\hline \multirow[t]{6}{*}{ MRT $^{a}$} & \multirow[t]{3}{*}{ Control } & Congruent & 927.8 (122.7) & 849.1 (106.9) & $845.7(117.3)$ & $858.1(160.8)$ \\
\hline & & Incongruent & $1043.4(130.4)$ & $972.9(112.3)$ & $998.0(145.8)$ & $952.9(122.8)$ \\
\hline & & Neutral & $932.5(136.6)$ & $839.2(127.5)$ & $835.9(132.2)$ & 808.8 (124.9) \\
\hline & \multirow[t]{3}{*}{ Preterm } & Congruent & $1070.5(133.9)$ & $987.1(146.4)$ & $989.9(162.6)$ & $985.6(189.4)$ \\
\hline & & Incongruent & $1131.5(155.6)$ & $1041.5(135.3)$ & $1037.4(179.2)$ & $1070.6(183.4)$ \\
\hline & & Neutral & 994.1 (153.6) & $989.6(132.2)$ & $1003.2(195.8)$ & $945.5(163.6)$ \\
\hline \multirow[t]{6}{*}{ Error rate } & \multirow[t]{3}{*}{ Control } & Congruent & $8.0(6.1)$ & $4.3(7.3)$ & $6.0(8.5)$ & $7.0(10.4)$ \\
\hline & & Incongruent & $10.7(10.7)$ & $9.3(9.4)$ & $13.0(11.0)$ & $12.7(13.8)$ \\
\hline & & Neutral & $8.7(7.8)$ & $8.0(9.5)$ & $4.0(6.9)$ & 7.3 (9.7) \\
\hline & \multirow[t]{3}{*}{ Preterm } & Congruent & $13.7(12.5)$ & $17.3(17.2)$ & $12.3(13.6)$ & $14.7(15.8)$ \\
\hline & & Incongruent & $23.0(16.9)$ & $24.3(18.1)$ & $23.7(19.9)$ & $22.7(16.1)$ \\
\hline & & Neutral & $19.7(17.5)$ & $15.7(15.3)$ & $15.7(17.9)$ & $11.0(12.9)$ \\
\hline
\end{tabular}

${ }^{\mathrm{a}} \mathrm{ms}$.

${ }^{b}$ percentage.

group than for the control group across most of the task conditions. To illustrate the magnitude of these differences for the preterm and full-term groups, respectively, mean MRT for the neutral condition collapsed across all cue types were $983.09 \mathrm{~ms}$ and $854.14 \mathrm{~ms}$, and mean errors for the corresponding condition were .16 and .07 ( $p$ 's <.01). Concerning the congruent condition collapsed across all cue types, the mean MRT was $1008.26 \mathrm{~ms}$ for the preterm and $1170.22 \mathrm{~ms}$ for the full-term children. Respectively, the mean errors for the corresponding condition were .14 and .06 ( $p$ 's $<.01)$. Finally, regarding the magnitude of these differences for the incongruent condition collapsed across all cue types were $1070.26 \mathrm{~ms}$ and $991.84 \mathrm{~ms}$, and mean errors for this condition were .23 and .11 ( $p$ 's <.05), respectively, for the preterm and for the full-term children.

\section{Group Comparisons Using the Subtraction and Interference Ratio Methods}

Results of ANOVAs comparing the two groups on the subtraction and interference ratio scores are listed in Table 2. Analysis of subtraction network scores revealed a significant group difference only for executive control, $F(1,48)=6.73$; $p=.013 ; \eta_{\mathrm{p}}^{2}=.123$, but not for the alerting, $F(1,48)=0.64$; $p=.43 ; \eta_{\mathrm{p}}{ }^{2}=.013$, or orienting, $F(1,48)=0.12 ; p=.73 ; \eta_{\mathrm{p}}{ }^{2}=$ .003. Analysis using the Interference Ratio Method indicated a similar pattern of findings, with a significant difference only for executive control, $F(1,48)=9.09 ; p=.004 ; \eta_{\mathrm{p}}{ }^{2}=$ .159 and not for alerting, $F(1,48)=0.05 ; p=.82 ; \eta_{\mathrm{p}}{ }^{2}=.001$, or orienting, $F(1,48)=0.13 ; p=.73 ; \eta_{\mathrm{p}}^{2}=.003$.

\section{Correlations Between Attentional Network Scores Computed by the Subtraction and Interference Ratio Methods}

Correlations between the subtraction and interference ratio scores for each of the three attentional networks was high, suggesting that the two scoring methods reflected similar constructs. Correlations for the preterm and control groups, respectively, were .888 and .641 for the alerting network, .860 and .601 for the orienting network, and .728 and .706 for the executive control network (all $p$ 's <.001).

\section{Correlations Among the Attentional Networks}

Table 3 presents the correlations between the network scores considered separately for the two types of scores (subtraction and interference ratio) for each group. Results confirm the independence of the network scores for both groups, the major exception being a robust correlation between the orienting and executive control network efficiency scores. According to results from a Fisher r-to- $Z$ transformation (Zimmerman, 1986), the correlation between these two scores was significantly higher for the preterm group than for the full-term group $(p=.004)$.

\section{DISCUSSION}

The aim of the present study was to explore the efficiency of the attentional networks identified by Fan et al. (2002) in preterm children at an early school age. We also sought to determine whether these three attentional networks were related in a preterm sample, as was found by Rueda et al. (2004) in full-term children. In initial analyses examining group differences across all task conditions, preterm children had generally slower MRT than full-term children, as is consistent with the results of Snyder et al. (2007). The latter differences justified controlling for MRT in analysis of the attention networks interference scores. In analyses of attention network efficiency using both the subtraction and interference ratio methods, we failed to observe group differences in alerting or orienting abilities. Thus, preterm children benefited from the presence of a preparatory cue as well as the full-term children and had no difficulty shifting their 
Table 2. Comparisons between the Preterm and the Control Group for the Subtraction and the Interference Ratio Scores

\begin{tabular}{|c|c|c|c|c|c|}
\hline Variable & Group & $M(S D)$ & Mean difference & $d f$ & $F$ \\
\hline \multicolumn{6}{|l|}{ Subtraction Method } \\
\hline \multirow{2}{*}{ Alerting } & Control & $74.7(44.7)$ & 19.5 & 1,48 & 0.625 \\
\hline & Preterm & $55.2(112.8)$ & & & \\
\hline \multirow[t]{2}{*}{ Orienting $^{\mathrm{a}}$} & Control & $13.8(63.4)$ & 8.3 & 1,48 & 0.124 \\
\hline & Preterm & $5.5(99.4)$ & & & \\
\hline \multirow[t]{2}{*}{ Executive control $^{\mathrm{a}}$} & Control & $121.6(86.9)$ & 59.6 & 1,48 & $6.73^{*}$ \\
\hline & Preterm & $62.0(75.1)$ & & & \\
\hline \multicolumn{6}{|l|}{ Interference Ratio Method } \\
\hline \multirow[t]{2}{*}{ Interference Alerting b } & Control & $9.1(7.4)$ & 0.7 & 1,48 & 0.05 \\
\hline & Preterm & $8.4(12.7)$ & & & \\
\hline \multirow[t]{2}{*}{ Interference Orienting ${ }^{\mathrm{b}}$} & Control & $3.2(7.3)$ & -0.9 & 1,48 & 0.13 \\
\hline & Preterm & $4.1(10.5)$ & & & \\
\hline \multirow[t]{2}{*}{ Interference Executive control ${ }^{\mathrm{b}}$} & Control & $14.6(8.4)$ & 7.5 & 1,48 & $9.09 *$ \\
\hline & Preterm & $7.1(8.9)$ & & & \\
\hline
\end{tabular}

$* p<.05$.

${ }^{\mathrm{a}} \mathrm{scores}$ in $\mathrm{ms}$.

bercentage.

attention across spatial location. In contrast, executive control abilities were significantly less well developed in preterm children than in full-term children. Consistent with Leclercq et al. (2006), this difference indicated a specific deficit in the ability to resist distractor interference in our preterm group, suggesting a negative impact of prematurity on executive control abilities.

The correlation analysis revealed a stronger relation between the executive control and orienting networks in the preterm children than in the full-term children, suggesting less differentiation between these two networks in the preterm group. Our results are similar to those obtained by Hrabok et al. (2006), who found that the executive control and orienting networks were related in children 4 to 5 years of age. The authors explained this association by proposing that the process of engaging, disengaging, and shifting required executive control abilities. A similar hypothesis is suggested by Posner and Rothbart (2000), who propose that orienting represents a more automatic form of executive control process. Leclercq et al. (2006) also found that the executive control and alerting networks were less differentiated in preterm than in full-term children, but modifications they made in the ANT task make it difficult to interpret their findings.

As demonstrated by Fan et al. (2003, 2005), the three networks are not only independent at a behavioral level but also at a neuroanatomic level. Therefore, it might be interesting to determine whether the less-segregated nature of the networks observed at a behavioral level could also be observed in preterm children at a neuronal activation level. These findings also suggest that differentiation among these networks may be delayed by prematurity, although longitudinal studies are needed to determine if differentiation occurs at a later age or persists as a more permanent feature of preterm birth.

Our findings confirm the utility of the Child ANT in identifying a specific executive control deficit in preterm children. This deficit was manifest as a weakness in inhibiting responses to nonpertinent task information. As this skill likely contributes to children's learning aptitudes, further research might examine the link between this deficit and academic competences of preterm children. Preterm children often show learning difficulties (Rickards et al., 2001), particularly in arithmetic (Anderson et al., 2003). Although

Table 3. Correlations among Alerting, Orienting, and Executive Control (EC) Network of the Subtraction and Interference Ratio Method for the Control and Preterm Groups separately

\begin{tabular}{|c|c|c|c|c|c|c|c|}
\hline \multirow[b]{2}{*}{ Method } & \multirow[b]{2}{*}{ Index } & \multicolumn{3}{|c|}{ Control $(N=25)$} & \multicolumn{3}{|c|}{ Preterm $(N=25)$} \\
\hline & & Alerting & Orienting & $\mathrm{EC}$ & Alerting & Orienting & $\mathrm{EC}$ \\
\hline \multirow[t]{3}{*}{ Subtraction } & Alerting & - & 0.026 & 0.319 & - & 0.250 & -0.011 \\
\hline & Orienting & & - & -0.007 & & - & 0.114 \\
\hline & $\mathrm{EC}$ & & & - & & & - \\
\hline \multirow[t]{3}{*}{ Interference } & Alerting & - & -0.061 & 0.193 & - & 0.306 & 0.239 \\
\hline & Orienting & & - & -0.018 & & - & $0.566 * * *$ \\
\hline & $\mathrm{EC}$ & & & - & & & - \\
\hline
\end{tabular}

$* * * p \leq .001$. 
deficits in executive function likely contribute to learning problems (Assel et al.,), less is known about the relationships between specific executive skills and children's academic competencies. For example, some studies report an association between inhibitory abilities and mathematics skills in young children (Espy et al., 2004). However, these relationships are less clear in older children (Bull, Espy, \& Wiebe, 2008).

A better appreciation of how executive abilities develop in preterm children is also of central importance in examining developmental outcomes in this population. As proposed by Anderson (2002), inhibition is a skill that emerges early in life and is essential for the development of other more complex executive abilities (i.e., planning). Executive control abilities such as behavioral self-regulation have also been linked to externalizing problems (Eisenberg, 2000). Early theory-driven assessment of attentional abilities, such as that used here, may be important for identifying children who are at risk for difficulties in executive control or other aspects of attention. This early identification may lead to the development of early interventions to address these problems, as it was recently proposed by Rueda and collaborators with preschool children (Tamm et al., in press).

\section{ACKNOWLEDGMENTS}

This work was partly supported by Swiss National Science Foundation (Number 32000B0-113632; Principal Investigator: Prof P. Hüppi). Authors Pizzo, Urben, Van der Linden, Hüppi, Borradori-Tolsa, Freschi, Forcada-Guex, and Barisnikov report neither personal or financial interests nor potential conflicts of interest.

\section{REFERENCES}

Anderson, P.J. (2002). Assessment and development of executive function (EF) during childhood. Child Neuropsychology, 8, 71-82.

Anderson, P.J., Doyle, L.W.; Victorian Infant Collaborative Study Group. (2003). Neurobehavioral outcomes of school-age children who were born very preterm or with extremely low birth weight in the 1990s. Journal of the American Medical Association, 289, 3264-3272.

Assel, M.A., Landry, S.H., Swank, P., Smith, K.E., \& Steelman, L.M. (2003). Precursors to mathematical skills: Examining the roles of visual-spatial skills, executive processes, and parenting factors. Journal of Applied Developmental Science, 7, 27-38.

Ayward, J.P. (2002). Cognitive and neuropsychological outcomes: More than IQ scores. Mental Retardation and Developmental Disabilities, 8, 234-240.

Bayless, S., \& Stevenson, J. (2007). Executive functions in schoolage children born very prematurely. Early Human Development, 83, 247-254.

Berger, A., Jones, L., Rothbart, M.K., \& Posner, M.I. (2000). Computerized games to study the development of attention in childhood. Behavior Research Methods, Instruments \& Computers, 32, 297-303.

Bhutta, A.T., Cleves, P.H., Cradock, M.M., \& Anand, K.J. (2002). Cognitive and behavioral outcomes of school-aged children who were born preterm. Journal of the American Medical Association, 288, 728-737.

Böhm, B., Katz-Salamon, M., Lagercrantz, H., \& Forssberg, H. (2002). Developmental risks and protective factors for influencing cognitive outcome at $51 / 2$ years of age in very-low-birthweight children. Developmental Medicine and Child Neurology, 44, 508-516.

Breslau, N., Chilcoat, H., DelDotto, J., Andreski, P., \& Brown, G. (1996). Low birth weight and neurocognitive status at six years of age. Biological Psychiatry, 40, 389-397.

Bull, R., Espy, K.E., \& Wiebe, S.A. (2008). Short-term memory, working memory and executive functioning in preschoolers: Longitudinal predictors of mathematical achievement at age 7 years. Developmental Neuropsychology, 33, 205-228.

de Frias, C.M., Dixon, R.A., \& Strauss, E. (2006). Structure of four executive functioning tests in healthy older adults. Neuropsychology, 20, 206-214.

Deforge, H., André, M., Hascoët, J.-M., Toniolo, A.-M., Demange, V., \& Fresson, J. (2006). Cognitive development and attention performances at school age of "normal" prematurely born children. Archives de Pédiatrie, 13, 1195-1201.

Dennis, M., Francis, D.J., Cirino, P.T., Schachar, R., Barnes, M.A., \& Fletcher, J.M. (2009). Why IQ is not a covariate in cognitive studies of neurodevelopmental disorders. Journal of the International Neuropsychological Society, 15, 331-343.

Edgin, J., Inder, T.E., Anderson, P.J., Hood, K.M., Clark, C.A., \& Woodward, L.J. (2008). Executive functioning in preschool children born very preterm: Relationship with early white matter pathology. Journal of the International Neuropsychological Society, 14, 90-101.

Eisenberg, N. (2000). Emotion, regulation, and moral development. Annual Review of Psychology, 51, 665-697.

Eisenberg, N., Guthrie, I.K., Fabes, R.A., Shepard, S., Losoya, S., Murphy, B.C., et al. (2000). Prediction of elementary school children's externalizing problem behaviors from attentional and behavioral regulation and negative emotionality. Child Development, 71, 1367-1382.

Elgen, I., Lundervold, A.J., \& Sommerfeld, K. (2004). Aspects of inattention in low birth weight children. Pediatric Neurology, 30, 92-98.

Espy, K.A., McDiarmid, M.D., Cwik, M.F., Meade Stalets, M., Hamby, A., \& Senn, T.E. (2004). The contribution of the executive functions to emergent mathematic skill in preschool children. Developmental Neuropsychology, 26, 465-486.

Espy, K.A., Stalets, M.M., McDiarmid, M.M., Senn, T.E., Cwik, M.F., \& Hamby, A. (2002). Executive functions in preschool children born preterm: Application of cognitive neuroscience paradigms. Child Neuropsychology, 8, 83-92.

Fan, J., Fossella, J., Sommer, T., Yanghong, W., \& Posner, M.I. (2003). Mapping the genetic variation of executive attention onto brain activity. Proceedings of the National Academy of Sciences United States of America, 100, 7406-7411.

Fan, J., McCandliss, B.D., Fossella, J., Flombaum, J.I., \& Posner, M.I. (2005). The activation of attentional networks. NeuroImage, 26, 471-479.

Fan, J., McCandliss, B.D., Sommer, T., Raz, A., \& Posner, M.I. (2002). Testing the efficiency and independence of attentional networks. Journal of Cognitive Neuroscience, 14, 340-347.

Fan, J., Wu, J., Fossella, J., \& Posner, M.I. (2001). Assessing the heritability of attentional networks. Neuroscience, 2, 14-20.

Fernandez-Duque, D., \& Posner, M.I. (2001). Brain imaging of attentional networks in normal and pathological states. 
Journal of Clinical and Experimental Neuropsychology, 23, 74-93.

Friedman, N.P., Miyake, A., Corley, R.P., Young, S.E., De Fries, J.C., \& Hewitt, J.K. (2006). Not all executive functions are related to intelligence. Psychological Science, 17, 172-179.

Harvey, J.M., O'Callaghan, M.J., \& Mohay, H. (1999). Executive function of children with extremely low birthweight: A case control study. Developmental Medicine and Child Neurology, 41, 292-297.

Hrabok, M., Kerns, K.A., \& Müller, U. (2006). The vigilance, orienting, and executive attention networks in 4-year-old children. Child Neuropsychology, 13, 408-421.

Kaufman, A., \& Kaufman, N. (1993). Batterie pour l'examen psychologique de l'enfant. Paris: ECPA.

Korkman, M., Kirk, U., \& Kemp, S. (2003). NEPSY: Bilan neuropsychologique de l'enfant-manuel: Les Editions du Centre de Psychologie Appliquée.

Largo, R.H., Pfister, D., Mohnari, L., Kundu, S., Lipp, A., \& Due, G. (1989). Significance of prenatal, perinatal and posnatal factors in the development of AGA preterm infant at five to seven years, Developmental Medicine and Child Neurology, 31, 440-456.

Leclercq, V., Jambaqué, I., Picard, A., Bricout, L., \& Siéroff, E. (2006). Trouble du contrôle attentionnel et prématuré. Revue de Neuropsychologie, 16, 41-64.

Manly, T., Anderson, V., Nimmo-Smith, I., Turner, A., Watson, P., \& Robertson, I.H. (2001). The differential assessment of children's attention: The Test of Everyday Attention for Children (TEA-Ch), normative sample and ADHD performance. Journal of Child Psychology and Psychiatry, 42, 1065-1081.

Nosarti, C., Giouroukou, E., Micali, N., Rifkin, L., Morris, R.G., \& Murray, R.M. (2007). Impaired executive functioning in young adults born very preterm. Journal of the International Neuropsychological Society, 13, 571-581.

Posner, M.I., \& Perterson, J. (1990). The attention system of human brain. Annual Review of Neuroscience, 13, 25-42.

Posner, M.I., \& Rothbart, M.K. (2000). Developing mechanisms of self-regulation. Development and Psychopathology, 12, 427-441.

Rickard, A.L., Kelly, E.A., Doyle, L.W., \& Callanan, C. (2001). Cognition, academic progress, behavior and self-concept at 14 years of very low birth weight. Journal of Developmental and Behavioral Pediatrics, 22, 11-18.

Ridderinkhof, K.R., van der Molen, M.W., Band, G.P., \& Bashore, T.R. (1997). Sources of interference from irrelevant information: A developmental study. Journal of Experimental Child Psychology, 65, 315-341.

Rueda, M.R., Fan, J., McCandliss, B.D., Halparin, J.D., Gruber, D.B., Lercari, L.P., et al. (2004). Development of attentional networks in childhood. Neuropsychologia, 42, 1029-1040.

Shum, D., Neulinger, K., O'Callaghan, M., \& Mohay, H. (2008). Attentional problems in children born very preterm or with extremely low birth weight at 7-9 years. Archives of Clinical Neuropsychology, 23, 103-112.

Snyder, E., Davis, D.W., Burns, B., \& Robinson, J. (2007). Examining attention networks in preschool children born with very low birth weights. Journal of Early Childhood and Infant Psychology, 26, 611-626.

Spieler, D.H., Balota, D.A., \& Faust, M.E. (1996). Stroop performance in healthy younger and older adults and in individuals with dementia of the Alzheimer's type. Journal of Experimental Psychology. Human Perception and Performance, 22, 461-479.

Tamm, L., McCandliss, B.D., Liang, A., Wigal, T.L., Posner, M.I., \& Swanson, J.M. (in press). Can attention itself be trained? Attention training of children at-risk for ADHD. In K. McBurnett (Ed.), Attention Deficit/Hyperactivity Disorder: A 21st Century Perspective. New York: Marcel Dekker.

Taylor, H.G., Hack, M., \& Klein, N.K. (1998). Attention deficits in children with $<750 \mathrm{gr}$ birth weight. Child Neuropsychology, 4, 21-34.

Taylor, H.G., Minich, N.M., Klein, N., \& Hack, M. (2004). Longitudinal outcomes of very low birth weight: Neuropsychological findings. Journal of the International Neuropsychological Society, 10, 149-163.

van de Weijer-Bergsma, E., Wijnroks, L., \& Jongmans, M.J. Attention development in infants and preschool children born preterm: A review. Infant Behavior and Development, 31, 333-351.

Zimmerman, D.W. (1986). Tests of Significance of Correlation Coefficients in the Absence of Bivariate Normal Populations. Journal of Experimental Education, 54, 223. 